\title{
Inclusion and the psychosocial experiences of students with visual impairments in a Zimbabwe state university
}

\author{
Ennie Manyumwa \\ Midlands State University, Zimbabwe.
}

Accepted 15 August, 2018

\begin{abstract}
This article explores inclusion and the psychosocial experiences of students with visual impairments in a Zimbabwe state university. The qualitative case study design was used and the participants comprised of six students with visual impairments. These were purposively sampled because of their experiences in the university. The semi-structured interview was the method used for data generation. Findings revealed that positive experiences of the students were a result of the support they got from friends and staff, the assistance they got with the curriculum, convenient hostel accommodation and effective traffic regulations. Such experiences made them feel confident and secure. The negative experiences were caused by the problematic registration process, limiting social environment, poor financial background and the students' perception of themselves. Resultant feelings were those of desperation, hopelessness, frustration and anxiety. They also felt different and not readily accepted. This necessitated educating the university community on inclusion and the need to respect diversity. There was also need for the students with visual impairments to be assertive and actively influence attempts made by the university to effect their inclusion.
\end{abstract}

Keywords: Inclusion, visual impairment, university, psychosocial, experiences.

E-mail: manyumwae@staff.msu.ac.zw.

\section{INTRODUCTION}

Inclusion has resulted in a growing number of students with disabilities having access to university education (United Nations Educational Scientific Organization, 1997). Among these students are those with visual impairments who now have the chance of receiving tertiary education alongside their sighted peers. The overall goal of inclusion in these universities is to maximise the specific skills that the students possess, their self-esteem and the overall quality of life for the students. Blindness and low vision which are the two major groups of visual impairment however, are physical conditions that are associated with deep emotional implications (Omede and Tenimu, 2013). This may be attributed to the fact that the students are in the low incidence group and in most cases are outnumbered by sighted students. The experiences of students with visual impairments in universities therefore, often depend on the treatment they get from the rest of the university community. It was the intention of this study to explore such experiences and their psychosocial effects on the students concerned.

The psycho-social effects associated with visual impairment range from positive ones which normally occur when the students have favourable experiences, to negative ones which normally result in the event of them facing adverse conditions. Among the factors that provide positive experiences for students with visual impairment, is the support given by people who constitute the university community, with close friends, peers and lecturers or mentors being the most likely ones to offer such support. A study carried out by Scott (2009) established that most undergraduate students with visual impairments in American universities acknowledged the importance of peers who assisted them with academic work, particularly in situations where the instructor's time was limited due to large class size. Relatedly, Sachs and Schreuer (2011) in their study of Israeli universities, established the importance of human support for students 
with visual impairments, especially for navigation around the campus and when they required assistance with reading and writing assignments. George and Duquette (2005) however, note that such support may be attributed to the personal virtues of the student with visual impairment, examples of which are the students' standing and advocacy skills.

The support given by lecturers and mentors contributes significantly to the positive experiences of students with visual impairments in a university. Crous (2004) established that when the students worked well with informed academic staff who were highly committed, who put the learning needs of the students into consideration and used teaching methods that compensated for their impaired vision, the students found life within the university bearable. Crous (2004) also noted that when the students with visual impairments were treated like all other students, they felt fully accepted and were encouraged to maintain a positive outlook on life. Scott (2009) in his study of American undergraduate students with visual impairments found out that students valued the role of supportive and nurturing mentors who displayed confidence in the students' abilities. All this goes to show how human support can be a source of positive experiences for students with visual impairments in a university setting.

The provision of assistive devices has a facilitative role which in turn has a positive impact on the functioning of students with visual impairments in a university. In a study of the inclusion of students with disabilities in a university in Zimbabwe, Chataika (2010) quoted a student with visual impairment who expressed appreciation for the provision made by the Disability Resource Centre which was established by the institution. The study showed that challenges were minimised through the services availed at the centre. According to Holloway (2001), positive experiences also generally occur when the students with visual impairments have access to funding for learning support needs and appropriate equipment.

The negative experiences of students with visual impairments may be caused by the negative assumptions that people may have towards students with visual impairments (Walker, 2008). These assumptions according to Walker (2008) are in most cases based on pity and the myths which people still hold from historical times when people with disabilities were viewed as incomplete or defective human beings. Slee et al. (2010) observed that many people still carry around a collection of prejudices and stereotyped ideas about people with disabilities which are largely based on fear, ignorance and lack of any first-hand experience with them. Relatedly, Choruma (2006) posits that negative beliefs on the causes of disability still persist in Zimbabwe where people generally associate disability with witchcraft. The traditional myths and beliefs that the university community may have towards the students with visual impairments therefore may cause them to view the students negatively.

For a person with visual impairment, social competence is a key component of a positive self-concept, high selfesteem, assertive behaviour and the ability to accept the disability as part of oneself (Wagner, 2004). Berry (2006) however, argues that creating social relationships with the university community may be difficult and complex for students with visual impairments. In a study of students with visual impairments in Canadian higher education institutions Reed and Curtis (2012) established that the students had difficulty in trusting anyone, something which might be a result of their inability to take in visual cues. According to Mitchell et al. (2007), evidence has it that students with visual impairments are more likely than their sighted peers to struggle with social isolation and rejection. Although this may be the case the students still need to be socialise with other students if their inclusion in the university is to be meaningful.

A university setting where marginalization and exclusion of students with visual impairments is practiced leaves the students psychologically and socially scarred (Kasiram and Sabrayen, 2013). Powell (2003) observes that students with low vision in particular, may be subjected to misunderstanding and outright prejudice very often because the sighted world may accuse them of pretending to be disabled. The students may therefore be caught in a dilemma. According to Ferrando et al. (2013), their self-assessment is usually made in a context of severe anxiety which can give rise to a self-perception of inefficacy and they may end up trying to conceal their disability or making excuses for incompetent behaviour. Powell (2003) says that the result is often isolation, inactivity or withdrawal.

The fear of isolation, workload concerns, low selfesteem and lack of self-advocacy skills often result in low confidence. According to Scaffa and Reitz (2013), high levels of depression have been found to correlate with severe visual impairments. Weiner et al. (2010) interviewed persons with visual impairments and noted three main themes associated with the psycho-social aspects of visual impairment as emotional challenges, negative emotional outcomes and indicators of emotional adaptation. Such emotional distress in these authors view hindered the students' ability to cope. The emotional challenges identified by the interviewees included lost independence, relinquishing of desired activities, lost spontaneity and negative impact on social interactions. In addition, they reported distressing emotional reactions such as depression, stigma and embarrassment, frustration and resignation. It is therefore evident from previous researches that creating social relationships is not easy for students with visual impairments.

\section{METHODOLOGY}

The objective of the study was to explore inclusion and the psychosocial experiences of students with visual 
impairments in a state university in Zimbabwe.

The transformative paradigm was used to guide the study. This paradigm was chosen because it places central importance on the lives and experiences of diverse groups which traditionally have been marginalised and it gives researchers an opportunity to engage their voices, with the aim of enhancing social justice (Mertens, 2009). The paradigm also offers a framework that encompasses the complexity within the disability community and leads to a full understanding of the genuine lived experiences of the participants (Tonette, 2011; Tashakkori and Teddle, 2010). Tashakkori and Teddle (2010) also advised the researchers who use this paradigm to channel the findings towards improving the lives of the participants. According to Mertens (2009), although the transformative paradigm does not have a specific set of methods or practices of its own the inclusion of a qualitative dimension is critical as a point of establishing dialogue between the researcher and the participants. Mertens (2009) further states that the researcher gets more out of the study by listening and valuing each participant's voice so that crystallisation occurs. It is for these reasons that the qualitative approach was used in the study.

Qualitative research concerns itself more with meaning, sense making and subjective experience more than the imposition of pre-conceived variables (Ritchie and Lewis, 2009; Silverman, 2011). Merriam (2009) notes that the researcher in qualitative research is the primary instrument in the generation and analysis of data, something which Denzin and Lincoln (2011) view as a shortcoming because of the potential biases which may arise and have an effect on the study. The use of multiple methods of data generation in this particular study served the purpose of guarding against such biases.

Since this study aimed at exploring inclusion and the psychosocial experiences of students with visual impairments in a state university in Zimbabwe the case study design was used. This design was chosen because of its ability to offer an intensive analysis of the experiences of the students; hence it comprised a lot of detail, richness, completeness and variance, leading to a thick description of their experiences of inclusion in the university (Somekh and Lewin, 2011; Litchitman, 2010). Although the design does not provide sufficient breadth for one to make generalisations (Yin, 2012) the results can be used as a basis for similar studies.

The sample for this study comprised of three students with blindness and three with low vision, making a total of six students. These students were chosen because they had particular characteristics, in this case visual impairment, which enabled a detailed exploration and understanding of the central themes that were intended for the study. It was necessary to keep the sample small enough to enable thorough analysis of data. This is in line with Ritchie and Lewis (2009) who suggest that qualitative research does not concern itself with prevalence, hence phenomena need to appear only once in order to be considered as part of the analytic map. Sampling therefore is often flexible and usually evolves as the study progresses until a point of redundancy in emerging themes has been reached (Saini and Shlonsky, 2012). The participants were selected using purposeful sampling. This strategy was preferred because it allows for the selection of information-rich cases from which a great deal of issues that are of central importance to the purpose of the research can be learnt (Merriam, 2009).

The data generation method used was the semistructured interview. This particular method was chosen because of its flexibility. Although it can be labour intensive, it offers a relatively open framework for data generation that often results in new themes and issues emerging in the process (Scott and Morrison, 2006).

\section{Data analysis}

Data generated through the semi-structured interview were transcribed. This was followed by reading and familiarising with the data (Meriam, 2009). Some notes and comments were written in the process and attached to the transcriptions, open coding as Merriam (2009) calls it. The open codes were then grouped systematically, a process which involved the interpretation and reflection on meaning. The list of groupings that emerged from interview data were then merged to form one master list of concepts, a process which Silverman (2011) refers to as collating of similar codes. This master list reflected the recurring patterns and subsequent categories, subthemes and main themes which were abstractions derived from the data and ultimately provided answers to the research objectives.

\section{RESULTS}

An exploration of the experiences of students with visual impairments in a university that practices inclusion yielded data which showed both positive and negative experiences.

\section{Positive experiences of students with visual impairments in the university}

The positive experiences of the students were categorised under the following; supportive friends, supportive staff, assistance with the curriculum, convenient accommodation and effective traffic regulations.

\section{Supportive friends}

The students acknowledged the assistance they got from their friends in the following areas: 
i. Mobility around the campus.

ii. Assistance with money for meals

iii. Research activities

iv. Discussion of content missed during lectures

v. Reading books to them

One student expressed her affection for her friends by using such terms as good, close to me and offer assistance whenever I need it, in time and also explained how this made life in the university much easier for her.

The support offered by friends reflects the great extent to which the students with visual impairments rely on other people for effective functioning in the institution since life in the university revolves around being at the right place at the right time and also involves a lot of reading and research. This shows that support from friends is inevitable for this student population. These findings are consistent with previous research that has proved the importance of human support for students with visual impairments in university settings (Scott, 2009; Sachs and Schreuer, 2011).

\section{Supportive staff}

Students described some staff members as being supportive in the following:

i. Selection of accommodation.

ii. Offer financial assistance

iii. Treat the students well

iv. Caring and willing to attend to requests.

They also expressed their appreciation for the staff at the Disability Resource Centre whom they described as good, caring, patient and helpful. Such words are indicative of people who show full acceptance of the students and are sensitive to their needs.

The students added that working with such staff made life on the campus bearable for them. This finding implies that the students did not only appreciate the care shown by friends but also the way the staff handle them. In his study of undergraduate students with visual impairments in American universities, Scott (2009) made similar observations where the students expressed their appreciation for caring people who showed their support. The students with visual impairments therefore, need to work with staff who understand them.

\section{Assistance with the curriculum}

Apart from supportive friends and staff, the students attributed their positive experiences to the assistance they got from the lecturers with academic work. They acknowledged that some lecturers gave clear explanations and that made them feel encompassed. The students however, used the words try and put effort to describe how the lecturers did this. Use of such words seems to suggest the willingness of the lecturers to assist although they may have lacked the competence and information needed on how to teach students with visual impairments and the strategies used to include such students into the main curriculum.

The students' positive experiences also resulted from the learning assistance which they got in the form of handouts and exam material in large print, commenting that it greatly assisted them with reading. In addition, they also mentioned that the adjustments made for them in terms of extended time during examinations enabled them to finish their work and make them compete on an equal basis with their sighted peers.

\section{Accommodation}

The allocation of single rooms was acknowledged by the students since:

i. This enabled them to work on their assignments without any disturbances

ii. There was 'more of quietness'.

iii. The rooms afforded them some privacy.

iv. They could set up their things the way in the way they wanted unlike what happens in shared rooms.

$v$. There was no discomfort which they normally felt when sharing

vi. They could bring their assistants into the room so that they could be helped with reading.

One student explained that whenever he shared a room with another student he would keep wondering what's happening by that other side. Use of such words seems to suggest anxiety, suspicion and lack of trust because the student would not be able to see what the room-mate would be doing. Reed and Curtis (2012) in their study of the experiences of students with visual impairments in Canadian higher education established that the students found it difficult to trust anyone. The allocation of single accommodation therefore contributed to the positive experiences for the students.

\section{Effective traffic regulations}

The students commented on how movement was made easy when traffic regulations were effected. Their reference to the chaos that was created whenever cars were randomly parked, the madness as one of the students referred to it, shows how much the students value the order and creation of space for movement in the campus environment. Comments given about the pedestrian crossings also show how much they appreciated the imposition of traffic regulations since it 
enabled them to move confidently without having to rely heavily on visual ability.

\section{Negative experiences of the students with visual impairments}

The negative experiences of the students were discussed under the following; problematic registration process, limiting social environment, effects of poor financial background and the students' perception of themselves. These are discussed in turn.

\section{Problematic registration process}

The students described the movement from one office to another as frustrating and the registration process as challenging due to non-payment of fees. The students explained that they could go for the whole semester without receiving fees from donor organisations that sponsored them. They also explained that although they were sometimes allowed to register, they would not access their results at the end of the semester as these would remain suppressed. One student clarified that although they were allowed to proceed to the next semester they would not learn with a free mind. These words are suggestive of the anxiety and uncertainty felt by the students since they would not be sure of their progress.

\section{Limiting social environment}

The students expressed concern at the discrimination they sometimes faced on the campus, with each of them describing different experiences. They related the surprise shown by other students, particularly those who had never been exposed to students with visual impairments and working with them on a day to day basis, such that same class sharing the same table. Use of the words $A h$ ! This guy is operating the same way we are doing! to me is an indication of astonishment on the part of the sighted students on realising that students with blindness could also participate and learn in the same way they did. The students explained how relations improved thereafter. This astonishment suggests the preconceived ideas that the sighted students held towards those with visual impairments, which ranged from not expecting to work side by side with them on a daily basis at a university, to surprise at noticing what the students with visual impairments could do. This confirms what Slee et al. (2010) said about many people still carrying around a collection of prejudices and stereotyped ideas about people with disabilities which were largely based on fear, ignorance and lack of any first-hand experience with them.

One of the students described how she was not accepted by sighted students who were not willing to interact with her or sit next to her, believing that blindness was contagious. She explained how this was a challenge and made her feel different and isolated. Walker (2008) acknowledges the fact that people often hold negative assumptions towards people with visual impairments which are in most cases based on pity, sin and myths and tend to avoid any situations where they might have to be directly involved with them.

One of the students was concerned with the stigmatization that he suffered because of the beliefs people had about blindness. He described the negative labels that had been given to them in the university under study, namely that blind people were; clumsy, beggars, rapists, lazy, do not want to do school work, and that they wanted to take advantage of their blindness. These beliefs according to the student were over generalized and resulted in depraved treatment and stigmatization of the students with visual impairments. Another student explained how he was not treated well or treated harshly and how other students took long to get used to him. He also expressed how it pained him and how he wished people would evaluate him as an individual first before painting him with the same brush as every other blind person. Kasiram and Subrayen (2013) stated that a university setting where marginalization and exclusion of students with visual impairments is practiced leaves the students psychologically and socially scarred. This seems to be evident from the findings of this study.

\section{Effect of poor financial background}

It was evident from the study that the students' financial background had a huge effect on their life in the university. This was conveyed by one student who commented that there were a lot of challenges that they faced but all of them circulated around their financial background. The student lamented that it was lack of money that had led to him being blind in the first place. He stated that his impairment could have been prevented if money to pay the optician had been available. His comment; without money you stay in that situation, to me is an indication of desperation.

The students acknowledged the assistance that they got from the donors. They however stated that the delay in payment of the fees led to the following challenges:
i. Struggling to make it.
ii. We always struggle.
iii. Challenges with registration.
iv. Paying for meals.
v. Not being able to access results.
vi. .. for us to suffer every day.
vii. Without money everything will just....

The use of such words as struggle and suffer are reflective of the dire situation which the students often 
found themselves in. One of the students could not complete the last statement for failure of words to express how emotional he was. Hutchinson et al. (1998) contend that when students with visual impairments reached university level, some of them faced extra costs in order to pay for assistive technology and accommodation, among other things. Hutchinson et al. (1998) however, note that financial constraints both at national and institutional level often resulted in general lack of resources being made available to facilitate the studies of these students. The students therefore had to rely on their own resources or on donors who usually delayed in disbursing the funds. This delay seemed to be a source of frustration and negatively affected the students with visual impairments in this particular study.

\section{Students' perceptions of themselves}

The students made constant comparison of themselves and their sighted peers. The constant use of such phrases as other students, one which was used several times, especially for us, and but for us, to me showed that they seemed to set themselves apart from the rest of the students. In his study of undergraduate students with visual impairments in American universities Scott (2009) described how the students felt that they were discriminated against, something which seems to be evident in this particular study.

Such expression as It's like, I look something different shows the effect that the treatment which one student got from other students had, on her self-concept. Another student also described how he felt frustrated and not at par with others, all of which are indicators of emotional challenges. The sentiments expressed by these students seem to confirm what Wiener et al. (2010) established in their study of persons with visual impairments. These researchers came up with emotional challenges, negative emotional outcomes and indicators of emotional adaptation as the main themes in their findings. One of the emotional challenges identified by the interviewees was frustration, the same word that was used by one student in this study, to describe how he felt. These findings are also consistent with those of Pow (2000) who investigated on the social experiences of students with visual impairments and established that the participants expressed frustration with being devalued and being treated differently from all other people. The participants also expressed annoyance at sighted people's tendency to equate lack of sight with lack of ability. Such emotional challenges have the potential to affect the students' ability to cope.

\section{CONCLUSIONS}

The aim of the study was to explore the inclusion and psychosocial experiences of students with visual impairments in a state university in Zimbabwe. These experiences were discussed under positive and negative experiences. The conclusions arrived at in relation to positive experiences are stated first, followed by those of the negative experiences.

\section{Students' positive experiences}

The students acknowledged the assistance they got from friends and colleagues with movement around the campus, money for meals, research and in other academic tasks like reading of books. They also commented on how some lecturers tried their best to accommodate them during the lectures. Such experiences made the students feel included and led to feelings of affection towards their friends who were there to assist them.

The provision of single rooms was another aspect that the students acknowledged as contributing immensely to their positive experiences within the institution as it assured them of their privacy and assisted them greatly where consistency with arrangement and order in the room was concerned. This led to the conclusion that allocation of single rooms alleviated the anxiety associated with having to share a room with another student, something which also made them feel secure and confident.

\section{Negative experiences of the students}

Findings revealed that the students with visual impairments faced challenges in the registration process which proved to be a frustrating experience since the setting was completely different from the one found in high school. The situation was compounded by the fact that they knew nobody and they were far away from family support.

From the findings it was evident that the students with visual impairments came from poor financial backgrounds and relied heavily on donor funding. This often led to delays in fees payment, something which subsequently interrupted their registration process. They were also not able to access their results in time and failed to pay for basic necessities like food. Such experiences caused them a lot of desperation and anxiety.

Findings showed that for some sighted students, it was their first time to learn alongside students with visual impairments as evidenced by the remarks of surprise and fear of contamination that they expressed. The conclusion that can be drawn is that sighted students held all sort of misconceptions about students with visual impairments, which might have been a result of stereotypical views about disability and lack of exposure to this student population. This in turn affected the students with visual impairments as it made them feel different and not readily accepted. 
It was evident that the students with visual impairments made constant comparison of themselves with their sighted peers. This made them view themselves as different from, and not at par with the rest of the students. Use of such words is indicative of a negative self-concept and lack of confidence in themselves. The conclusion that can be drawn is that the students with visual impairments did not feel fully included and still regarded themselves as different, feelings which were likely to negatively affect their experiences in the university.

It was evident from the findings of this study that most of the negative experiences of the students with visual impairments were a result of the hostile social environment which was created by the university community's lack of awareness of the need to accommodate them. This calls for the need to educate the university community, lecturers and sighted students on issues concerning the inclusion of students with visual impairments and the need to respect diversity, hence enhance social justice.

There is also need for assertiveness on the part of the students with visual impairments. Instead of waiting for inclusion to just happen they need to make their voices heard and actively influence any attempts made by the university to effect their inclusion, hence improve their experiences within the institution.

\section{REFERENCES}

Berry, R. A. (2006). Inclusion, power and community: Teacher and students interpret the language of community in an inclusion classroom. American Educational Research Journal, 43(3): 489-529.

Chataika, T. (2010). Inclusion of disabled students into higher education in Zimbabwe. In J. Lavinia, \& M. Moore, Cross-cultural Perspectives on Policy and Practice: Decolonizing Community Contexts (pp. 116-131). New York: Routledge.

Choruma, T. (2006). The forgotten tribe: People with disabilities in Zimbabwe. London: Progressio.

Crous, F. (2004). The social needs and problems of higher education students with impairments. Acta Academia, 36(2): 200-220.

Denzin, N., and Lincoln, Y. (2011). The SAGE handbook of qualitative research. Thousand Oaks: SAGE Publications Inc.

Ferrando, P., Pallero, R., and Anguiano-Carrasco, C. (2013). Measuring anxiety in visually impaired people: A comparison between the linear and the non-linear. Psicologica, (34): 383-406.

George, A., and Duquette, C. (2006). The psycho-social experiences of a student with low vision. Journal of Visual Impairment and Blindness, 100(3): 152-163.

Holloway, S. (2001). The experiences of higher education from the perspectives of disabled students. Disability and Society, 16(4): 597615.

Hutchinson, J. O., Atkinson, K., and Orpwood, J. (1998). Breaking down barriers: Access to further and higher education for visually impaired students. Cornwall: Stanley Thornes Publishers Ltd.

Kasiram, M., and Subrayen, R. (2013). Social exclusion of students with visual impairment at a tertiary institution in Kwa-Zulu Natal. South African Family Practice, 55(11): 66-72.

Litchitman, M. (2010). Qualitative research in education: A user's guide $\left(2^{\text {nd }}\right.$ Ed.). California: SAGE Publicatons Inc.

Mertens, D. M. (2009). Transformative research and evaluation. New York: The Guilford Press.
Mitchell, S., Maxine, S., and Whittaker, S. (2007). Low vison rehabilitation: A practical guide for occupational therapists. New Jersey: SLACK Incorporated.

Omede, A., and Tenimu, S. (2013). Counselling persons with visual impairment for effective career choice: Implications for national development. Journal of Emerging Trends in Educational Research and Policy Studies, 4(2): 345-349.

Powell, S. (2003). Special teaching in higher education: Successful strategies for access and inclusion. London: Kegan Page Ltd.

Reed, M., and Curtis, K. (2012). Experiences of students with visual impairments in Canadian higher education. Journal of Visual Impairment and Blindness, 106(7): 414-425.

Ritchie, J., and Lewis, J. (2009). Qualitative research practice: A guide for social science students and researchers. Thousand Oaks: SAGE Publications Inc.

Sachs, D., and Schreuer, N. (2011). Inclusion of students with disabilities in higher education: Performance and participation in students' experiences. Disability Studies Quarterly, 31(2), 1-24.

Saini, M., and Shlonsky, A. (2012). Systematic synthesis of qualitative research. Oxford: Oxford University Press.

Scaffa, M. E., and Reitz, M. S. (2013). Occupational therapy: Community-based practice settings $\left(2^{\text {nd }}\right.$ Ed.). Philadelphia: F. A. Davis Company.

Scott, D., and Morrison, M. (2006). Key ideas in educational research. London: Continuum International Publishing Group.

Scott, R. (2009). Undergraduate educational experiences: The academic success of college students with blindness and visual impairments. Parkway: ProQuest LLC UMI 3395269.

Silverman, D. (2011). Qualitative research ( $3^{\text {rd }}$ Ed.). London: SAGE Publications Inc.

Slee, R., Weiner, G., and Tomlinson, S. (Eds.) (2010). School effectiveness for whom? London: Falmer Press.

Somekh, B., and Lewin, C. (2011). Theory and methods in social research. London: SAGE Publications Inc.

Tashakkori, A., and Teddle, C. (2010). SAGE handbook of mixed methods in social and behavioural research. Thousand Oaks: SAGE Publications.

Tonette, S. R. (2011). Challenging ableism, understanding disability, including adults with disabilities in workplaces and learning spaces. San Francisco: John Wiley \& Sons.

UNESCO (1997, August). Disabled students at universities in Africa. UNESCO Sub-Regional Office for Sothern Africa, Harare, Zimbabwe.

Wagner, E. (2004). Development and implementation of a curriculum to develop social competence for students with visual impairment in Germany. Journal of Visual Impairment and Blindness, 98(11): 703709

Walker, C. L. (2008). Counsellor attitudes towards persons who are blind or visually impaired. East Eisenhower Parkway: ProQuest LLC.

Wiener, W. R., Welsh, R. L., and Blasch, B. B. (2010). Foundations of orientation and mobility. New York: American Foundations for the Blind Press.

Yin, R. K. (2012). Qualitative research from start to finish. New York: The Guilford Press.

Citation: Manyumwa, E. (2018). Inclusion and the psychosocial experiences of students with visual impairments in a Zimbabwe state university. African Educational Research Journal, 6(3): 190196. 